\title{
Tuberculosis and migration: a review
}

N.M. Kronfol ${ }^{1}$ and Z. Mansour ${ }^{1}$

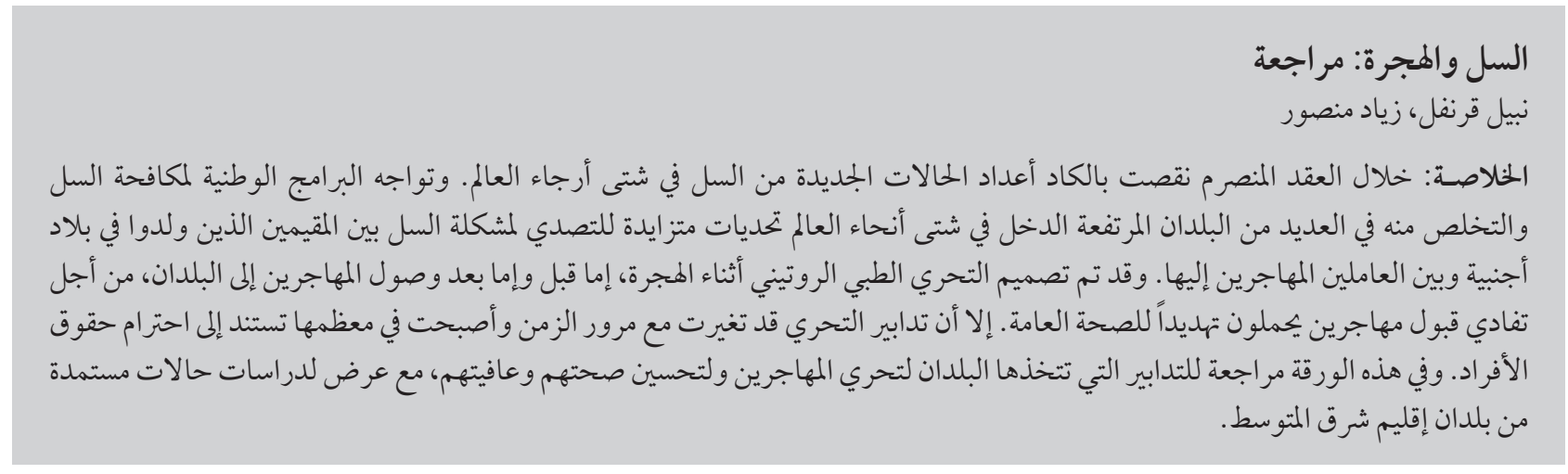

ABSTRACT In the past decade, the number of new cases of tuberculosis worldwide has barely declined and national tuberculosis control and elimination programmes in many high-income countries worldwide are increasingly challenged to address the problem of disease in foreign-born residents and migrant workers. Routine immigration medical screening, either before or after arrival in the recipient country, is designed to avoid the admission of migrants who pose a public health threat. Screening measures, however, have changed with time largely based on respect for individuals' rights. This paper reviews the measures that are being used by countries to screen immigrants and improve their health well-being, and presents cases studies from two Eastern Mediterranean Region countries.

\section{Tuberculose et migration : analyse}

RÉSUMÉ Au cours des dix dernières années, le nombre de nouveaux cas de tuberculose dans le monde a peu diminué et les programmes nationaux de lutte contre la tuberculose et d'élimination de cette maladie dans de nombreux pays à revenu élevé sont de plus en plus confrontés au problème posé par les cas d'infection chez des résidents nés à l'étranger et des travailleurs migrants. Le dépistage médical systématique des candidats à l'immigration, soit avant, soit après l'arrivée dans le pays d'accueil, a été organisé afin d'éviter l'admission de migrants qui représentent une menace pour la santé publique. Toutefois, les mesures de dépistage ont évolué dans le temps principalement afin de respecter les droits des personnes. Le présent article examine les mesures appliquées par les pays pour dépister les immigrants et améliorer leur état de santé et leur bien-être, et présente des études de cas de deux pays de la Région de la Méditerranée orientale. 


\section{Introduction}

When Robert Koch presented his discovery of the tuberculosis (TB) bacillus in March 1882, he hoped it would lead to the eradication of "this terrible plague of mankind". More than a century later, TB remains a leading killer, especially of people with HIV infection; drugresistant strains continue to spread; and paediatric TB remains an area of neglect $[1,2]$. In the past decade, the number of new cases of TB worldwide has barely declined, and the number of deaths remains catastrophic.

Historically, human migration has had a major impact on the spread of TB [3]. Since the 1980s, migration has reached an unprecedented scale. National TB control and elimination programmes (NTPs) in many highincome countries worldwide are increasingly challenged to address the problem of disease in foreign-born residents and migrants. Immigration policies and shifting migration patterns over the past 5 decades have brought larger numbers of permanent and temporary residency migrants from regions of the world with a high incidence of active TB (> 40 per 100000$)$ into areas with a low incidence ( $<25$ per 100000$)$ [4]. As a consequence, both national immigration policies and global health strategies for the control of TB share a common interest in the health of mobile populations who may be moving from high-to-low incidence regions [5].

This shift in migration patterns from regions of the world with elevated $\mathrm{TB}$ prevalence has combined to affect markedly the epidemiology of the disease in immigration-receiving nations. Table 1 shows that in developed, low-incidence countries the proportion of new TB patients who were foreign-born was as high as $85 \%$. Investigation of TB in foreign-born residents of immigrationreceiving nations shows that most cases of TB in migrant cohorts are due to reactivation of TB infection acquired before arrival [6]. Transmission of TB from foreign-born individuals infected after arrival does occur, but this transmission most commonly takes place within defined socioeconomic or cultural groups [7], including high-risk clusters such as homeless people, chronic alcoholics and the migrant community itself.

The relationship between international migration and TB control has been extensively addressed by a report of a European task force from the International Union Against Tuberculosis and Lung Disease and the World Health Organization (WHO) in 1994 [8], and a review of publications on the impact of migration from high to low TB-incidence countries has compared the cost-effectiveness of different TB control strategies [9].

\section{Screening immigrants for tuberculosis}

For more than 100 years, one strand of the immigration policy of the major industrialized nations has included the medical examination of migrant workers [10-12]. Immigration screening originally took place after immigrant arrival at quarantine and medical stations; a classic example is provided by the facility at Ellis Island in the United States of America (USA). After the First
World War, major immigration-receiving nations established offshore medical screening systems, conducted before the migrants' departure [13]. That model when applied to $T B$ is intended to reduce the importation of disease, and has been used by nations with extensive international immigration recruitment programmes such as Australia, Canada and the USA. Other nations, including several in Europe, have continued to use on-arrival screening and assessment to identify and manage imported infections such as TB.

The goal of detecting active, infectious pulmonary $\mathrm{TB}$ is a key component of all of these programmes. The regular screening of higher risk migrants entering European nations was recommended in the mid-1990s. Recent surveys indicate that as many as half of the nations do not have organized screening programmes, and that there is considerable divergence in the application of existing programmes in those that do [14]. Increasing attention to the issue of TB and migration has stimulated renewed interest in screening [3].

Routine immigration medical screening is most often designed to avoid the admission of migrants who pose a public health threat. As a consequence, immigration-related TB screening was designed to manage

\begin{tabular}{|c|c|c|}
\hline Country & $\begin{array}{l}\text { No. of cases reported } \\
\text { in } 2003\end{array}$ & $\begin{array}{l}\% \text { cases in foreign- } \\
\text { born population }\end{array}$ \\
\hline Australia & 1013 & 80 \\
\hline Canada & 1451 & 66 \\
\hline France & 5740 & 41 \\
\hline Germany & 6526 & 38 \\
\hline Israel & 505 & 85 \\
\hline Netherlands & 1282 & 61 \\
\hline Norway & 320 & 76 \\
\hline Switzerland & 554 & 51 \\
\hline United Kingdom & 6400 & 64 \\
\hline United States of America & 14861 & 51 \\
\hline
\end{tabular}

Source: Adapted from World Health Organization 2005 [49]. 
active pulmonary disease that could be transmitted person-to-person. As active infectious pulmonary disease presents the greatest public health risk, medical screening of immigrants for TB has been primarily based on chest radiography, reflecting the historical, logistical and operational legacies of those principles $[3,15,16]$. In spite of its widespread use, routine radiological screening has diagnostic and prognostic limitations [17].

Routine TB screening by radiology is commonly applied to immigrant applicants, beginning in mid-adolescence. This practice reflects historical clinical experience, suggesting that most paediatric pulmonary cases are paucibacillary, and the risk of secondary TB transmission from an infected child is low. As a consequence, most immigration-related TB screening is not focused on the management of paediatric $\mathrm{TB}$ infection or disease [18]. The diagnosis of TB in children and the shifting epidemiology of TB disease, including HIV coinfected individuals, have implications for paediatric $\mathrm{TB}$ care that may require reconsideration of current approaches.

For most nations with pre-departure screening programmes, migrants with active, infectious TB disease are denied admission and referred for treatment before arrival; those with inactive, latent TB infection (LTBI) or non-infectious presentations are referred for public health follow-up and clinical management after arrival. Nations using onarrival screening commonly refer active and latent disease to local authorities for management and follow-up.

\section{Barriers to screening migrants for tuberculosis}

Migrants can face several local and national policy barriers that could limit access to public health control and health-care treatment programmes, including TB services. These may be institutional, such as when services are unavailable for the uninsured. Fear of interacting with local health-care providers and subsequent referral to immigration or security services may also limit access to care for the irregular migrants or illegal aliens [19]. Barriers to access, due to language, cultural or social factors, may also be encountered. National policies and strategies developed to deal with these barriers include the provision of services for migrants without charge, and the establishment of centres with cultural competency and linguistic capacity for diverse populations [20].

Migrants and refugees are, at least initially in the post-arrival period, more likely to reside in major urban rather than rural settings. The urbanization of case burden can generate additional resource pressures on metropolitan areas faced with other public health issues (homeless people, substance abusers and those living with HIV/AIDS).

In summary, studies suggest that existing schemes for medical screening for $\mathrm{TB}$ in migrants may have some degree of effectiveness in reducing the risk of importation of contagious TB $[21,22]$. Moreover, most $\mathrm{TB}$ cases presenting in migrants occur after the immediate arrival period and are believed to represent reactivation of LTBI [23].

\section{Latent tuberculosis infections}

Migration from high-prevalence areas has introduced large numbers of latently infected people to lower incidence, migrant-receiving nations. Without preventive treatment, some of those individuals will experience disease reactivation related to the natural history of TB infection. The routine detection and management of LTBI has not been a primary component of immigration medical screening in the countries carrying out this examination.
The effect of admission of migrants with LTBI is an issue of current investigation in many low TB-incidence nations with active immigration processing programmes. Because of its lack of sensitivity, radiological screening alone will not detect latent disease in infected people. Radiological screening, while useful in identifying abnormalities suggestive of pulmonary disease in high-incidence situations is not a tool for the detection of LTBI. In the absence of targeted screening for LTBI, future reactivation of latent disease in foreign-born residents can be predicted to continue to generate domestic TB cases, in spite of migrant worker screening programmes [24].

Testing foreign-born migrants for LTBI is only one part of the potential solution to reducing the risk of imported $\mathrm{TB}$ on the domestic disease burden. Only a small number of individuals with LTBI will progress to active disease [25]. It is often estimated that the lifetime risk of active $\mathrm{TB}$ is about $10 \%$ in the immune-competent TBinfected host, with about half of that risk in migrants occurring during the first 3-5 years after arrival [26]. Given the prevalence of LTBI in migrant populations from high-endemic TB regions, providing management services that include appropriate preventive treatment for LTBI would be a major undertaking for clinical programmes. Design and implementation of such programmes would need to be accompanied by consideration of the effect of several other factors, including surveillance, notification, contact tracing, reporting, monitoring, evaluation, delivery, sideeffects, compliance and cost-benefits, in addition to social enforcement issues.

\section{Efficacy of screening}

The issue of surveillance of communicable diseases and screening of migrant workers for TB is a politically sensitive topic, and robust evidence is needed 
about the burden of migrant-associated $\mathrm{TB}$ and the efficacy of screening services $[9,23,27]$. A systematic review and meta-analysis was undertaken by Arshad et al. to determine the yield of active screening for $\mathrm{TB}$ among new migrants at the point of entry [28]. The yield for pulmonary $\mathrm{TB}$ varied across categories is shown in Table 2.

Overall, it has been found that the proportion of screened migrants with active pulmonary TB, from 1 and 38 per 1000, is between 10 to 100 times greater than the prevalence measured in the general population of the host country (Table 3). Refugees especially have been shown to be 4 times more likely to be diagnosed with active pulmonary $\mathrm{TB}$ than other migrants [28]. Refugees usually leave their own countries as a consequence of critical and rapidly developing events, and are therefore less likely to be subject to selection based on their health status, the so called "healthy immigrant effect" [29]. Furthermore, refugees may spend some time in overcrowded camps before moving to the host country; in these settings the living conditions may favour both the transmission and the relapse of TB. Not only is the prevalence of $\mathrm{TB}$ higher in immigrants that the host country, it has also been noted that the prevalence of $\mathrm{TB}$ among immigrants is higher than expected from the WHO estimated prevalence of $\mathrm{TB}$ in the country of origin [28]. This suggests that migrants are a group with a higher risk for active ТВ [30].

\section{Country screening programmes}

Screening for TB was implemented in a number of industrialized countries shortly after the Second World War, when refugees from Europe were found to have high rates of active TB. These early screening programmes employed chest radiography, which was popular in that era as a method of detection of TB [31]. However, mass screening of the general population has since been abandoned, not only because the incidence of TB in the general population has declined, but also because it was demonstrated repeatedly that such screening had no appreciable impact on the overall rates of morbidity or mortality [32].

\section{Europe}

Most European countries offer some form of on-arrival TB screening for migrants. Some screen at ports of entry and others at specialist centres once migrants have arrived in the community; screening may be systematic or voluntary [23]. Evidence supporting the effectiveness of these different approaches is lacking, hence identifying models of best practice remains difficult. However, almost all high-income, industrialized countries, with the exception of Italy, continue to utilize chest radiography screening for the detection of active $\mathrm{TB}$ among applicants for permanent residence [33].

In the United Kingdom, migrants undergo radiography at international ports on arrival, and are subsequently referred to the health authority of the district of intended residence [34]. This approach has been criticized for its lack of cost-effectiveness and efficiency in detecting early cases, with experts claiming that the process is inconsistent, poorly run and often discriminatory. Since 1971, the port of arrival scheme notifies the local consultant for communicable disease control of all new entrants who come from a country where the incidence of $\mathrm{TB}$ is $>40$ per 100000 and who intend to stay for more than 6 months. Those with symptoms may be offered a chest radiograph at the port of entry. The consultant for communicable disease control, in turn, notifies the local TB services for follow-up treatment.

Permanent entry into Switzerland requires screening of all migrants for TB from countries other than the European Union (EU), European Free Trade Agreement countries not in the EU, North America, Australia and New Zealand, and the process is part of the administrative function of the transit camps where migrants are accommodated.

Transit camps are also used in Norway for all asylum seekers. The health services in Norway have an obligation

\begin{tabular}{|c|c|c|c|}
\hline Category & $\begin{array}{l}\text { No. of cases found per } \\
1000 \text { screened }\end{array}$ & $95 \% \mathrm{Cl}$ & Heterogeneity I $^{2}$ statistic \% \\
\hline Refugees & 11.9 & $6.7-17.2$ & 92 \\
\hline Asylum seekers & 2.8 & $2.0-3.7$ & 96 \\
\hline Regular immigrants & 2.7 & $2.0-3.4$ & 81 \\
\hline Immigrants from Europe & 2.4 & $1.3-3.4$ & 51.5 \\
\hline Immigrants from Africa & 6.5 & $3.2-10.0$ & 62 \\
\hline Immigrants from Asia & 11.2 & $6.2-16.1$ & 95 \\
\hline Total migrants & 3.5 & $2.9-4.1$ & 94 \\
\hline
\end{tabular}

Source: Arshad et al. [28].

$\mathrm{Cl}=$ confidence interval. 


\section{Mnnmmnnm}

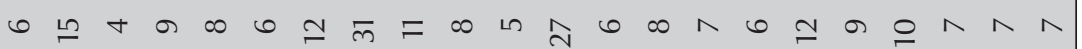

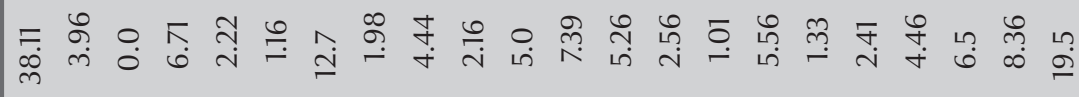

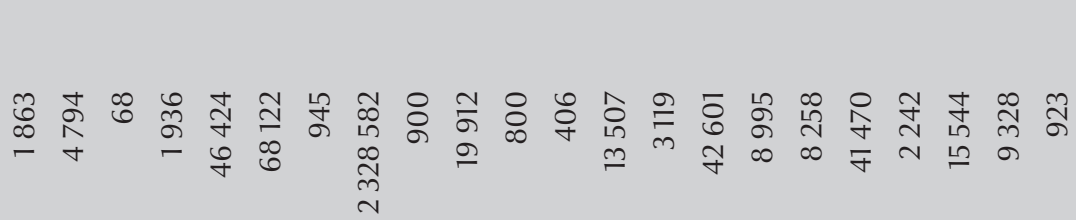

$\Xi$

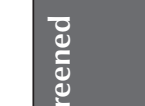


to carry out $\mathrm{TB}$ screening on those persons from countries with high $\mathrm{TB}$ prevalence. Screening occurs within days of arrival.

In the Netherlands, applicants undergo a screening chest radiograph within 1 week of arrival and at 6-month intervals for 2 years thereafter [35]. Immigrants, foreign students and foreign workers from high TB-prevalence countries (> 50 cases per 100000 ) who intend to stay more than 3 months, are referred by the immigration office to the municipal health service for screening. Compliance with this procedure is high because the residence permit is only issued if screening has been performed. A study from the Netherlands reports that a large proportion of patients with TB, even when smear-positive, may have no complaints [36]. Voluntary periodic screening (biannual) is offered to all migrants $>12$ years of age, with BCG vaccination, for 2 years. Migrants between 12 and 25 years without a BCG vaccination receive 2 tuberculin skin tests 2 months apart. If the skin test is positive, radiography follow-up screening (biannual) for 2 years is recommended; in selected cases, preventive therapy is offered.

\section{North America and Australia}

Australia, Canada and the USA ask for pre-entry examinations for those planning a stay of more than 6 months, but Canada is selective about the countries of origin on which it imposes that policy.

For applicants to Canada, screening chest radiographs are performed in the place where the application is made, either overseas or within Canada [37]. Applicants with LTBI and an abnormal radiograph consistent with a prior $\mathrm{TB}$ infection (so-called "inactive TB") are referred to the Canadian health authorities for follow-up after immigration.

Australia has for a long time implemented a national reception policy for migrants. "Particular care" is taken to screen for $\mathrm{TB}$, which is an automatic bar to gaining a visa [38]. Two-step tuberculin skin testing prior to departure, followed by single-step tuberculin testing after return, is recommended for travellers.

\section{Case studies on migrant screening from the Eastern Mediterranean Region}

\section{Oman}

Oman has been able to reduce its burden of TB by $85 \%$ in less than 25 years [39], yet migrant workers are known to pose many health challenges in the country. Identified or suspected TB cases diagnosed by the private healthcare system have to be immediately referred to the public system for treatment and follow up. The public health system provides free TB treatment to everyone [40]. Private pharmacies are not allowed to purchase or sell any TB medication.

Around one-third of Omani inhabitants are immigrants from the Indian subcontinent, an area with a high prevalence of TB. Migrants are screened for active TB in their home country before being granted work visas. Repeat screening is carried out within 1 month of arrival, and then every 2 years. If active TB cases are confirmed, or individuals are suspected of having TB, based on abnormal chest $\mathrm{X}$-rays, they are normally not granted a visa. Furthermore, as an extra measure to prevent TB transmission, expatriates developing $\mathrm{TB}$ during their stay in the country are deported after conversion to smear-negative. This deportation is commonly referred to as "the repatriation policy". However, the fear of repatriation prevents expatriates from seeking health-care services, especially when they know that they have TB. Thus, the repatriation policy is seen as imposing a barrier to early detection and effective treatment of expatriates, which in turn affects overall $\mathrm{TB}$ control in the country. It has been suggested that this policy be revised, and that alternative policies and strategies be developed to improve TB control in Oman [41].

In a series of interviews with different health-care providers to explore the roles played by the migrant population and the private health-care sector in relation to TB control identified some challenges and barriers to TB control in Oman [42]. These challenges were mainly related to the unintended negative consequences arising from the current repatriation policy of immigrants and to the lack of involvement of the private sector in TB control. Health-care providers perceive $\mathrm{TB}$ as an imported disease, which is brought into Oman by expatriates [42]. Most suggested the need for strict control of expatriates' entry into the country and considered that the current screening tests for expatriates were insufficient and sometimes ineffective. The participants acknowledged, however, that the repatriation policy might cause expatriates to hide and travel home before treatment [42]. They urged that this policy be re-evaluated, and that policies aimed at improving the health seeking behaviours of the expatriates be adopted. In addition, most respondents in the public health sector commented on the need for better regulation of the private clinics and hospitals by the Ministry of Health and for greater involvement of the private sector in the NTP. Private sector practitioners were perceived as being primarily driven by client demands, rather than by disease control priorities, thus they may deliberately avoid reporting expatriate TB patients to help them avoid repatriation.

\section{Lebanon}

Lebanon has a low burden of TB; the estimated incidence of new smearpositive TB cases is 6 per 100000 inhabitants with 235 new smear-positive cases per year [43], but it is notable that the number of non-Lebanese TB cases increased between 2002 (48 cases) 
and 2010 (171 cases). The NTP offers free laboratory tests and examinations for all TB patients resident in Lebanon whatever their nationality. Medications and hospital treatment are made available free.

Reliable estimates suggest that Lebanon employs close to 180000 foreign workers and that some 40000 come into the country every year. About $70 \%$ of these workers come from Ethiopia, considered a high-prevalence TB country. The remaining 30\% come principally from Sri Lanka, the Philippines and Indonesia [44]. Most of these foreign workers enter Lebanon through Beirut airport. One characteristic of these migrant domestic workers in Lebanon is that most are living in the households of their employers, who are relatively well-to-do families, and not within their respective communities as is the case in most European countries. This is to say that the new living environment in Lebanon is quite different from the case of immigrants to highincome industrialized countries, who may live in conditions of poverty often in slums with other migrants mostly from the same country. In addition to these domestic workers, there are several hundred of thousands of workers in Lebanon from EMR countries such as the Syrian Arab Republic who are exempt from residency requirements. Unlike the housemaids, Syrian, Egyptian and Sudanese immigrants work as manual labourers, watchmen, in petrol service stations, as construction workers or in the field and have far less contact with families and households. They travel frequently back and forth to their country to visit their families.

Several options have been considered for screening migrant workers: screen the prospective workers in their own country prior to travel; screen the prospective workers on arrival to Beirut airport; screen the prospective workers within a finite period of time after arrival; or continue as present. These options are discussed below.
Screen prospective workers in their own country. The NTP had recommended this in its annual report [44]. In fact, all migrant workers do undertake examinations prior to leaving their respective country as one component of the formalities required. In principle, this is the optimal solution for all concerned. However it hinges on the credibility of the laboratory in the country of origin and may impose an additional cost burden especially for migrants living in rural areas.

Screen prospective workers on arrival to Beirut airport. This has also been proposed by the NTP. This would require the installation of a diagnostic facility inside the perimeter of the airport. Arriving workers would be screened on arrival prior to entering Lebanon. In terms of monitoring, this is undoubtedly the optimal solution. However there are concerns about stigmatization. Moreover, cost-effectiveness is a real issue because the cost per case detected has been estimated at about US\$3000.

Screen prospective workers within a finite time after arrival. This option requires that domestic workers are screened at one of the accredited laboratories in Lebanon within a certain period time after arrival. It should be noted that this measure is currently being pursued by most households to ensure that their live-in help is safe for the family members.

Continue as present. Another option is to keep matters as they are and to detect TB when symptoms appear, with the proviso that the patient is referred for treatment at NTP premises. The problem of repatriation remains acute, as a patient under treatment is unlikely to be employed when other healthier workers are available. This would raise the risk of patients hiding from the authorities and thus threatening the health of the public. The disincentive of repatriation is real for recruitment offices since they will have to shoulder the cost of travel and forego a substantial part of their earnings.
Public perceptions of screening migrants

Migration, drug resistance and HIV infection have contributed to the re-emergence of $\mathrm{TB}$ as a major public health problem in Europe, North America and Australia. Screening immigrants for TB has generated considerable media, political and public health interest [38]. Although screening of migrants is widespread in recipient countries and is a key recommendation in TB control guidelines, it has been criticized as being ineffective, of poor value, discriminatory, stigmatizing, racist and divisive [45]. Acceptability to recipients is universally acknowledged as an ethical prerequisite for any screening programme [46], the more so for programmes that may be compulsory and that target potentially vulnerable groups. Screening of immigrants for TB has been carried out for at least 50 years; yet the views of recipients about its acceptability remain unknown. Some screening programmes are voluntary, whereas others are mandatory. Even mandatory screening is often carried out without coercion. Compliance is ensured in several ways, for example if the screening result is a requirement for a residence permit, access to health care or social benefits or permission to work.

Acceptability is an essential but neglected ethical prerequisite of screening programmes, particularly those targeting immigrants and refugees. One qualitative interview study of $53 \mathrm{im}$ migrants who were offered screening for $\mathrm{TB}$ in east London in fact found that the opportunity to be screened for $\mathrm{TB}$ was valued highly by recipients [45]. Moreover, many saw being screened as a socially responsible activity. Of the minority raising concerns, few mentioned the possibility of discrimination. Acceptability was high irrespective of the setting, with respondents expressing preference for their chosen place of screening. The overwhelming majority 
of informants welcomed screening and felt reassured by the process. This was expressed as a sense of security or relief, particularly after a negative screening result. Others sawscreening as "a privilege" and "a good idea". Being screened was seen as a socially responsible activity, reducing the chances of $\mathrm{TB}$ becoming a problem for the host country. Some felt that the wider settled population should also have access to screening. Others, interviewed with their families, felt that screening should be particularly promoted for children.

\section{Conclusion}

Migration from high TB-incidence areas of the world will continue to be one of the most important factors in determining TB epidemiology in the developed world. Lessons learnt from
NTPs in immigrant-receiving nations might benefit and support policy and programme coordination and international harmonization within the global TB control strategies [47].

The principles of TB control, elimination and eradication provide specific context regarding the interface between national and international interests in development, global public health, policy harmonization and integrated programme delivery. For example, a comparison of 3 strategies for the control of TB among migrants to the USA concluded that government's underwriting of the expansion of the DOTS strategy in Mexico, the Dominican Republic and Haiti was the most effective long-term approach to reducing TB-related morbidity and mortality among migrants from those countries and would produce net savings in the USA [48]. These projected domestic benefits should encourage the governments of developed countries to provide substantial and sustained funding for the control of TB abroad.

Nations without current formal immigration screening programmes, but with growing immigration levels, could learn valuable lessons from those countries that have long-standing medical screening programmes. TB provides a window through which the globalization of other health issues can be modelled. The effectiveness of welldefined, existing legislative and regulatory processes can be studied in the light of international health and infectious disease challenges in both clinical and public health sectors. These lessons may have relevance for those managing emerging health issues in an increasingly globalized world.

Competing interests: None declared.

\section{References}

1. Lönnroth $\mathrm{K}$ et al. Tuberculosis control and elimination 2010-50: cure, care, and social development. Lancet, 2010, 375:1814-1829.

2. Keshavjee S, Farmer PE. Picking up the pace-scale-up of MDR tuberculosis treatment programmes. New England Journal of Medicine, 2010, 363:1781-1784.

3. Rieder HL et al. Tuberculosis control in Europe and international migration. European Respiratory Journal, 1994, 7:1545-1553.

4. An expanded DOTS framework for effective tuberculosis control. Geneva, World Health Organization, 2002 (WHO/CDS/ TB/2002.297).

5. MacPherson DW, Gushulak BD. Balancing prevention and screening among international migrants with tuberculosis: population mobility as the major epidemiological influence in low-incidence nations. Public Health, 2006, 120:712-723.

6. Marks GB et al. Effectiveness of postmigration screening in controlling tuberculosis among refugees: a historical cohort study, 1984-1998. American Journal of Public Health, 2001, 91:1797-1799.

7. Sterling TR et al. A multi-state outbreak of tuberculosis among members of a highly mobile social network: implications for tuberculosis elimination. International Journal of Tuberculosis and Lung Disease, 2000, 4:1066-1073.

8. Cliff A, Haggett P. Time, travel and infection. British Medical Bulletin, 2004, 69:87-99.

9. Dasgupta K, Menzies D. Cost-effectiveness of tuberculosis control strategies among immigrants and refugees. European Respiratory Journal, 2005, 25:1107-1116.

10. Technical instructions for medical examination of aliens in the United States. Atlanta, Georgia, Centers for Disease Control and Prevention, 1991.
11. Conducting an immigration medical examination. In: Designated medical practitioner handbook. Section 6. Ottawa, Citizenship and Immigration Canada, 2009 (http://www. cic.gc.ca/english/resources/publications/dmp-handbook/ index.asp, accessed 22 June 2013).

12. Instructions for medical and radiological examination of Australia visa applicants. Canberra, Health Policy Section, Department of Immigration and Citizenship, 2009 (http://www. immi.gov.au/gateways/panel_doctors/conducting_medicals/instructions/panel-doctor-instructions-vers-jan-2008. pdf, accessed 22 June 2013 ).

13. Binkin NJ et al. Overseas screening for tuberculosis in immigrants and refugees to the United States: current status. Clinical Infectious Diseases, 1996, 23:1226-1232.

14. Dye $\mathrm{C}$ et al. Evolution of tuberculosis control and prospects for reducing tuberculosis incidence, prevalence, and deaths globally. Journal of the American Medical Association, 2005, 293:2767-2775.

15. Tala E, Liippo K. Still screening for pulmonary tuberculosis? European Respiratory Journal, 1989, 2:397-398.

16. Gordin FM et al. Presumptive diagnosis and treatment of pulmonary tuberculosis based on radiographic findings. American Review of Respiratory Disease, 1989, 139:1090-1093.

17. Underwood BR et al. Contact tracing and population screening for tuberculosis-who should be assessed? Journal of Public Health Medicine, 2003, 25:59-61.

18. Mandalakas AM, Starke JR. Tuberculosis screening in immigrant children. Pediatric Infectious Disease Journal, 2004, 23:71-72.

19. Post-detention completion of tuberculosis treatment for persons deported or released from the custody of the Immigra- 
tion and Naturalization Service-United States, 2003. Morbidity and Mortality Weekly Report, 2003, 52:438-441.

20. Houston HR, Harada N, Makinodan T. Development of a culturally sensitive educational intervention program to reduce the high incidence of tuberculosis among foreign-born Vietnamese. Ethnicity and Health, 2002, 7:255-265.

21. Johnsen NL et al. Cohort analysis of asylum seekers in Oslo, Norway, 1987-1995: effectiveness of screening at entry and TB incidence in subsequent years. International Journal ofTuberculosis and Lung Disease, 2005, 9:37-42.

22. Floyd K. Costs and effectiveness-the impact of economic studies on TB control. Tuberculosis, 2003, 83:187-200.

23. Coker $\mathrm{R}$ et al. Tuberculosis screening in migrants in selected European countries shows wide disparities. European Respiratory Journal, 2006, 27:801-807.

24. Taylor Z, Nolan CM, Blumberg HM; American Thoracic Society; Centers for Disease Control and Prevention; Infectious Diseases Society of America. Controlling tuberculosis in the United States. Recommendations from the American Thoracic Society, CDC, and the Infectious Diseases Society of America. Morbidity and Mortality Weekly Report, 2005, 54 RR-12;1-81.

25. Horwitz O, Wilbek E, Erickson PA. Epidemiological basis of tuberculosis eradication. 10. Longitudinal studies on the risk of tuberculosis in the general population of a low-prevalence area. Bulletin of the World Health Organization, 1969 41:95-113.

26. Uppaluri A et al. Effectiveness of the Immigration Medical Surveillance Programme for tuberculosis in Ontario. Canadian Journal of Public Health, 2002, 93:88-91.

27. Hargreaves S, Carballo M, Friedland JS. Screening migrants for tuberculosis: where next? Lancet Infectious Diseases, 2009, 9:139-140.

28. Arshad S et al. Active screening at entry for tuberculosis among new immigrants: a systematic review and meta-analysis. European Respiratory Journal, 2010, 35:1336-1345.

29. McDonald JT, Kennedy S. Insights into the 'healthy immigrant effect': health status and health service use of immigrants to Canada. Social Science and Medicine, 2004, 59:1613-1627.

30. Erkens $\mathrm{C}$ et al. Coverage and yield of entry and follow-up screening for tuberculosis among new immigrants. European Respiratory Journal, 2008, 32:153-161.

31. Binkin NJ et al. Overseas screening for tuberculosis in immigrants and refugees to the United States: current status. Clinical Infectious Diseases, 1996, 23:1226-1232.

32. Toman K. Tuberculosis-case-finding and chemotherapy: questions and answers. Geneva, World Health Organization, 1979.

33. Rapiti E et al. Determinants of tuberculosis in an immigrant population in Rome: a case-control study. International Journal of Tuberculosis and Lung Disease, 1998, 2:479-483.

34. Van den Bosch CA, Roberts JA. Tuberculosis screening of new entrants; how can it be made more effective? Journal of Public Health Medicine, 2000, 22:220-223.

35. Bwire R et al. Tuberculosis screening among immigrants in The Netherlands: what is its contribution to public health? Netherlands Journal of Medicine, 2000, 56:63-71.

36. Verver S, Bwire R, Borgdorff MW. Screening for pulmonary tuberculosis among immigrants: estimated effect on severity of disease and duration of infectiousness. International Journal of Tuberculosis and Lung Disease, 2001, 5:419-425.

37. Dasgupta $\mathrm{K}$ et al. Comparison of cost-effectiveness of tuberculosis screening of close contacts and foreign-born populations. American Journal of Respiratory and Critical Care Medicine, 2000, 162:2079-2086.
38. Paterson R. Screening immigrants for infectious diseases. Lancet Infectious Diseases, 2003, 3(11):681.

39. Al-Maniri A et al. Towards the elimination of tuberculosis in a developing country: 25 years of tuberculosis control in Oman. International Journal of Tuberculosis and Lung Disease, 2007, 11:175-180.

40. Tuberculosis manual, 3rd ed. Muscat, Oman, Ministry of Health, 2007.

41. Littleton J et al. Migrants and tuberculosis: analysing epidemiological data with ethnography. Australian and New Zealand Journal of Public Health, 2008, 32:142-149.

42. Al-Maniri A et al. Immigrants and health system challenges to TB control in Oman. BMC Health Services Research, 2010, $10: 210$.

43. Tuberculosis. Country profile-Lebanon. World Health Organization [online database] (http://www.who.int/tb/country/ data/profiles/en/index.html, accessed 22 June 2013).

44. Annual report, National tuberculosis programme. Beirut, Lebanon, Ministry of Public Health, 2010

45. Brewin P et al. Is screening for tuberculosis acceptable to immigrants? A qualitative study. Journal of Public Health, 2006, 28:253-260.

46. Criteria for appraising the viability, effectiveness and appropriateness of a screening programme. UK National Screening Committee [online] (http://www.screening.nhs.uk/criteria, accessed 22 June 2013).

47. Fanning EA. The impact of global tuberculosis in Canada: We are our brothers' keepers. Canadian Journal of Infectious Diseases and Medical Microbiology, 1995, 6:225-227.

48. Schwartzman $\mathrm{K}$ et al. Domestic returns from investment in the control of tuberculosis in other countries. New England Journal ofMedicine, 2005, 353:1008-1020.

49. Global tuberculosis control: surveillance, planning, and financing. WHO Report 2005. Geneva, World Health Organization, 2005 (WHO/HTM/TB/2005).

50. Kelly PM, Scott L, Krause VL. Tuberculosis in east Timorese refugees: implications for health care needs in East Timor. International Journal of Tuberculosis and Lung Disease, 2002, 6:980-987.

51. Van den Brande P et al.; VRGT (Flemish Lung and Tuberculosis Association). Tuberculosis in asylum seekers in Belgium. European Respiratory Journal, 1997, 10:610-614.

52. Denburg A et al. Initial health screening results for Karen refugees: a retrospective review. Canada Communicable Disease Report, 2007, 33:16-22

53. Wilcke JT et al. Tuberculosis in a cohort of Vietnamese refugees after arrival in Denmark 1979-1982. International Journal of Tuberculosis and Lung Disease, 1998, 2:219-224.

54. Van Burg JL, Verver S, Borgdorff MW. The epidemiology of tuberculosis among asylum seekers in The Netherlands: implications for screening. International Journal of Tuberculosis and Lung Disease, 2003, 7:139-144.

55. Smith A et al. Outcome of medical screening of Kosovan refugees in Ireland: 1999. Communicable Disease and Public Health, 2000, 3:291-294.

56. Akhtar S, Mohammad HG. Nonlinear pattern of pulmonary tuberculosis among migrants at entry in Kuwait: 1997-2006. BMC Public Health, 2008, 8:264.

57. Hobbs $\mathrm{M}$ et al. The health status of asylum seekers screened by Auckland Public Health in 1999 and 2000. New Zealand Medical Journal, 2002, 115:U152.

58. Rysstad OG, Gallefoss F. TB status among Kosovar refugees. International Journal of Tuberculosis and Lung Disease, 2003, 7:458-463. 
59. Salinas Solano C et al. Tuberculosis en la población inmigrante de Bilbao [Tuberculosis among immigrants in Bilbao (Spain)] Archivos de Bronconeumologia, 2002, 38:506-510.

60. Monney M, Zellweger JP. Active and passive screening for tuberculosis in Vaud Canton, Switzerland. Swiss Medical Weekly, 2005, 135:469-474.

61. Laifer G et al. Polymerase chain reaction for Mycobacterium tuberculosis: impact on clinical management of refugees with pulmonary infiltrates. Chest, 2004, 125:981-986.

62. Laifer $G$ et al. TB in a low-incidence country: differences between new immigrants, foreign-born residents and native residents. American Journal of Medicine, 2007, 120:350-356.

63. Mathez $\mathrm{C}$ et al. Active screening for pulmonary tuberculosis among immigrants by chest x-ray at the Swiss border. Swiss Medical Weekly, 2007, 137:649-654.

64. Harling $\mathrm{R}$ et al. Tuberculosis screening of asylum seekers: 1 years' experience at the Dover Induction Centres. Public Health, 2007, 121:822-827.
65. Callister ME et al. Pulmonary tuberculosis among political asylum seekers screened at Heathrow Airport, London, 1995-9. Thorax, 2002, 57:152-156.

66. Ormerod LP. Is new immigrant screening for tuberculosis still worthwhile? Journal of Infection, 1998, 37:39-40.

67. Pitchenik AE et al. The prevalence of tuberculosis and drug resistance among Haitians. New England Journal of Medicine, 1982, 307:162-165

68. Nolan CM, Elarth AM. Tuberculosis in a cohort of Southeast Asian Refugees. A five-year surveillance study. American Review of Respiratory Disease, 1988, 137:805-809.

69. Judson FN et al. Health status of Southeast Asian refugees. Western Journal of Medicine, 1984, 141:183-188.

\section{Systematic screening for active tuberculosis: principles and recommendations}

There have been calls to revisit the experiences of tuberculosis (TB) screening campaigns that were widely applied in Europe and North America in the mid-20th century, as well as more recent experiences with TB screening in countries with a high burden of the disease, and to assess their possible relevance for TB care and prevention in the 21 st century. In response, the World Health Organization (WHO) has developed guidelines on screening for active TB. An extensive review of the evidence has been undertaken. The review suggests that screening, if done in the right way and targeting the right people, may reduce suffering and death, but the review also highlights several reasons to be cautious. As discussed in detail in Systematic screening for active tuberculosis: principles and recommendations, there is a need to balance potential benefits against the risks and costs of screening; this conclusion is mirrored by the history of TB screening. Systematic screening for active tuberculosis: principles and recommendations presents the first comprehensive assessment by $\mathrm{WHO}$ of the appropriateness of screening for active TB since the recommendations made in 1974 by the Expert Committee. However, the relative effectiveness and cost-effectiveness of screening remain uncertain, a point that is underscored by the systematic reviews presented in this guideline. This document sets out basic principles for prioritizing risk groups and choosing a screening approach; it also emphasizes the importance of assessing the epidemiological situation, adapting approaches to local situations, integrating TB screening into other health-promotion activities, minimizing the risk of harm to individuals, and engaging in continual monitoring and evaluation. It calls for more and better research to assess the impact of screening and to develop and evaluate new screening tests and approaches.

Further information about this and other WHO publications is available at: http://apps.who.int/bookorders/anglais/ home1.jpp?sesslan=1 